$\checkmark$ Research Square

\title{
Social Media use and Sexual Behaviour of Undergraduate Students in a Nigerian University
}

Endurance Uzobo ( $\square$ enduzobo@gmail.com )

Niger Delta University https://orcid.org/0000-0002-8180-8268

\section{Ruth Ovieakini Enoch}

Niger Delta University

\section{Research Article}

Keywords: Social media, Sexual behaviour, WhatsApp, Instagram, uses and gratification theory

Posted Date: June 10th, 2020

DOl: https://doi.org/10.21203/rs.3.rs-34051/v1

License: (9) This work is licensed under a Creative Commons Attribution 4.0 International License. Read Full License 


\section{Abstract}

While studies have generally explored the implication of social media on education, crime, and communication, there is a paucity of studies exploring the influence of social media on sexual behaviour. Thus, this study aims to investigate the role of social media on sexual behaviour among 195 undergraduate students in the Niger Delta University, Bayelsa, Nigeria. This cross-sectional study was anchored on the uses and gratification theory (UGT). Data for this study were generated through the use of a structured questionnaire, while data analysis was done at the univariate, bivariate and multivariate levels. Findings shows that the average age of students was 22.72 . Also, the study found out that the use of WhatsApp (OR $=15.349, p<0.05)$, Instagram $(O R=0.254, p<0.05)$, time spent on the social media (OR = $0.123, p<0.05)$ were significantly associated with high-risk sexual behaviour in model I. While relationship status $(\mathrm{OR}=24.289, \mathrm{p}<0.01)$ was associated with high-risk sexual behaviour in model II. The study, therefore, concluded that the use of social media influences the sexual behaviour of undergraduate. Hence, the study recommended sex education to help expose undergraduate students to the dangers involved in spending excessive time on social media.

\section{Introduction}

Most aspect of our social life is drastically changing in recent times. The world is now connected more than ever before, the revolution in the telecommunications sector has therefore increased internet access and use among the general population, particularly young people (France \& Roberts, 2015). Social media has blossoms rapidly in the past decade particularly with the development of web 2.0, which has led to tremendous changes in how people meet and relate in person-centred, convenient, meaningful and boilable ways (Blanchard, 2011). With the use of social media, relationship building has become easier and cheaper.

The social media are internet-based applications that are accessible through smartphones and computer devices. Social media platforms such as Facebook, WhatsApp, Twitter, Instagram, YouTube and Snapchat have become so popular that is hard to find a teen or youth in the urban centres who do not possess one of these applications (Lindsay, 2011). It is an undisputed fact that these applications are changing virtually everything now more than ever.

Before this period, making friends and starting a relationship was purely done through the traditional means of face-to-face social interaction in specific physical places and physical community spaces such as school, churches, parties and clubs. But now, people interact and make friends with immediate and far away people sometimes without even seeing them (Bailey \& Barbara, 2014). The downside to this phenomenon is that people do not get to know the true nature of the person they are making friends with. Thus, the social media is also serving as a tool particularly for teen sexual predators (Livingston, Haddon, \& Görzig, 2012; Wolak, Finkelhor, Mitchell, \& Ybarra, 2010; Akhuetie, Uzobo \& Ogbeide, 2017). Hence, this 
component of the internet; the social media sites are fast turning into a danger zone especially for teenagers whose online profiles often attract aggressive sexual predators.

The story of Cynthia Osokogu, a 25-year-old lady murdered by two friends which she met on social media, specifically Facebook cannot be forgotten in a hurry. The suspects, after luring Cynthia from Nasarawa state to Lagos in a hotel, drugged her, raped her severally before finally strangling her to death. This story is one in a million cases in Nigeria where many young people especially young female teenagers are deceived by online predators who afterwards exploit them as best as they can (Akhuetie, Uzobo Ogbeide, 2017).

Different studies have shown a sharp rise in the number of online sexual predators who prowl the internet looking for vulnerable teenagers, then make arrangements to meet them for illicit sexual activities (Livingstone, Haddon, \& Görzig, 2012; Nissley, 2008, Wolak, \& Finkelhor, 2008; Wurtele, \& Kenny, 2010). Chat rooms of different social network platforms are often the places where internet predators go to deceive teens for illicit sexual activities.

A by Business Day (2013), found that social media accounted for, by far, more traffic of Nigerian youth on the internet than any other services and the sex-related activities are a major attraction. A healthy feeling of wanting to be admired, touched, loved and cared for by another person is natural and is expected to develop in young people as they grow, the social media create these opportunities for young adults in discussion that may lead to the satisfaction of these needs. Media platforms provide a unique atmosphere conducive for expression and discussion of all forms of sexuality, without the traditional oversight of parents, family members and others in the society (Galupo, Davis, Grynkiewicz \& Mitchell, 2014). However, the associated risks with using social media such as exposing young adults to sex, having multiple sexual partners and sexting have been found to likely lead to depression and risk of HIV/AIDS and other sexually transmitted diseases (Hayes, 2010).

\section{Literature Review}

Several studies have attempted documenting the link between youth exposure to social media content and sexual activities. For instance, Collins et al. (2004) stated that viewing sexual content in media contributes to increased sexual activity among youth. The study of Brown and L'Engel (2008) also found that youth's exposed to heavier sexual content across media were more likely to have had sexual intercourse.

Concerning social media, facts are emerging that online social networking positively relates to sexual behaviour, such as the formation of an intimate sexual relationship and indulgence in sexual practices, such as unsafe sex and multiple sex partners (Ajayi, 2010). In Nigeria, the studies of Adebayo, Udegbe and Sunmola (2006), Iwokagh, Agbana, and Agbana (2014) and Kujuni (2012) supported that electronic media predispose youth to risky sexual behaviour. 
Again, Adebayo, Udegbe and Sunmola (2006) in examining the relationship between gender, internet use and sexual behaviour orientation among young Nigeria, concluded that gender and internet have an overwhelming influence on sexual behaviour. Hence, they demonstrated that as the use of the internet increased, male participants reported a greater extent of risky sexual behaviour orientation than their female counterparts.

In a similar note, Ashiekpe and Ugande (2017) research on the effects of social media sexting on adolescents and youth sexual behaviour in Nigeria also revealed that sexting has saturated social media platforms with pornographic content and all social media users are advertently or inadvertently vulnerable to this growing trend. This study further indicated that Nigerian adolescents and youth are reaching puberty earlier and engaging in sexual intercourse earlier than before.

Also in the study of Business Day (2013), it was discovered that those who use social media platform like Twitter, Facebook, YouTube and Instagram are more likely to be exposed to sexual activities compared to counterparts that use other forms of media. They also added that adolescents users of social media with primary education are more likely to be involved in sexual activities.

Despite all the studies highlighted above, there is still a reasonable gap to be covered in the study of social media use and sexual behaviour. For instance, none of the studies above actually looked at this trend among undergraduate students in Nigerian universities. In light of the above studies, there are limited numbers of studies addressing social media use and sexual behaviour especially in the southsouth region of Nigeria. Again, most of the studies highlighted above have not particularly addressed the influence of social media use on numbers of sex partners, use of contraceptives, frequency of sex and age at which undergraduates first engage in sexual intercourse. This study has been designed to bridge this gap.

\section{Theoretical Framework}

The theoretical framework for this study is built on the uses and gratification theory (UGT). This theory is traced to the 1940s when researchers in the united states became inquisitive about reasons for viewing traditional media especially radio and TV programmes including soap operas and game quiz shows. Most studies then concluded that different people use the media for different motivation and purpose. Katz, Gurevitch and Haas (1973) argued that people use the media for five important reasons, cognitive, affective, personal integrated, social integrity and tension release needs, according to Katz et al. (1973) cognitive needs include using the media to acquire information, knowledge and understanding, effective stands for emotional needs include pleasure and feelings, personal integrated needs. With regards to the internet and the new media, Ruggiero (2000) highlighted three main categories of use and gratification.

- Content users of the internet; the need for finding specific information which is gratified with contents. 
- Process users; gain gratification from the experience of purposeful navigating or random browsing of the internet in its functional process.

- Social users; using the internet for a wide range of forming and depending on social ties.

UGT provides insight into how and why youths use social media to fulfil certain needs and gratifications. This theory is thus, relevant to understanding why undergraduates with access to mobile phones and the internet may deliberately manipulate social media contents to meet certain needs. Park, Kee and Valenzuela (2009) found out that undergraduates joined Facebook out of their need to socialize with their friends, in search of status and social recognition, they had this discovery from an internet survey of university undergraduates in Texas. The intensity of Facebook use was strongly related to other gratifications such as feelings of personal satisfaction, confidence, and participation in civic life.

In conclusion, UGT stresses that people, especially youths, seek social media to meet certain needs. However, sexual curiosity peaks in youths, due to hormonal changes, which may result in youth interest in sex. The curiosity for sexual satisfaction may further be exacerbated by easy access to explicit sexual materials online (Wusuo, 2013) heavy exposited that as people are responsible for the content they generate and consume (Peter \& Valkenburgs, 2011).

\section{Research Methods}

\section{Research Locale}

This study adopted a cross-sectional survey to study 195 undergraduate students in the Niger Delta University, Bayelsa State, Nigeria. This study was conducted in the Niger Delta University, located in Wilberforce Island of Bayelsa State, Nigeria between September to October 2019. The university is about $32 \mathrm{~km}$ from the state capital Yenagoa. The university with a current population of about 16,000 was founded in 2001. It is a state-funded university established in the year 2000 by the late chief DSP Alamieyeseigha, the then governor of Bayelsa state. In 2017, the Nigeria university system statistical digest of 2017, from the national university commission reported a total student enrolment of 14,547 for the Niger Delta University in Bayelsa state.

\section{Sampling Techniques}

The study recruited 195 undergraduate students to be part of the study. In selecting the sample, the simple random sampling techniques were employed to randomly pick two (2) departments each from the faculty of social sciences, education and management sciences and one each from the other faculties. Two departments each were picked from the above-mentioned faculty based on the fact that there are more students enrolled in programmes residing at those faculties. In sum, fifteen departments were randomly selected; namely: department of sociology, department of political science, department of jurisprudence, department of public law, department of educational foundations, department of teacher 
education, department of theatre arts, department of banking and fiancé, department of business administration, department of chemical sciences, department of mental health and psychiatry, department of crop and soil science, department of pharmacy and pharmacy practice, department of medical laboratory science, department of psychiatry and department of civil engineering. Furthermore, the stratified sampling technique was used to further divide the students into two (2) groups; male and female. This is to enable both groups to be represented in the study. Lastly, the accidental sampling/convenient sampling technique was used to sample the available set of students in reading halls and other parts of the academic environment.

\section{Methods of Data Collection}

The data used for this study was primarily obtained through the use of the questionnaire designed based on the research objectives. The questionnaire was divided into three sections. Section A elicited information of the socio-demographic characteristic which include; age, relationship status, gender, religion, year of study, estimated allowance per month, current CGPA, academic status, ethnic affiliations, residence pattern, type of family, and type of browsing device used; Section B was made up of questions on the use of social media which includes; number of social media account, rate of use of different social media platforms, average hour spent on social media in a day, most common activity online, age in the use of social media, average volume of data used per month, place of access to social media; Section C was made up of questions relating to sexual behaviour which include; ever had sex, ever had an abortion, ever had a sex partner, number of sexual partners in the past, number of sexual partners currently, use of condoms, description of sexual life, use of other forms of contraceptives, age at first sexual intercourse, sexual practices mostly engaged in, last time engaged in sex.

\section{Methods of Data Analysis}

Data collected for this study were manually checked for errors before imputing them into IBM SPSS computer software for analysis. Variables in the study were thus described using frequencies and percentages, bar charts and logistic regression. The logistic regression model was used to access the strength of association between the dependent and independent variables. In all analysis, the base for rejection was set at a p-value of 0.05 .

\section{Independent Variables}

Independent variable in this study is social media, represented in the use of Facebook, Twitter, Instagram, YouTube and WhatsApp. Also, the level at which these media accounts were used was measured at the ordinal level with categories like (1) high (2) moderate (3) low. 


\section{Dependent Variables}

The dependent variable in this study is sexual behaviour, represented by age at first sex, number of sexual partners and the use of contraceptives. Thus, sexual behaviour was measured with items such as age at first sexual intercourse with responses categories such as (1) less than a year (2) 15-19 years (3) 19-24 years (4) 25 years and above. This was later reclassified to high, moderate and low. Furthermore, the number of sex partner presented with responses like (1) none (2) 1 (3) 2 (4) 3 (5) 4 (6) 4 and above, still, this was also classified to high, moderate and low. Others can be seen in the variable definition in Table 1 below.

\section{Ethical Approval}

All research procedures performed in this study adheres to the ethical standard of the Niger Delta University, which is also in line with the national code of researching in Nigeria. The research process is also in line with the Helsinki 1964 declaration and its later amendments or comparable ethical standards.

Thus, this study was reviewed and approved by the Research Committee of the Department of Sociology of the Niger Delta University, Bayelsa State Nigeria, with Approval Number:

NDU/SOC.SC./SOCIOLOGY/ETHICS-COM/018. Also, the participation of the respondents was voluntary and no respondent was persuaded or finally induce to participate in the study. Also, respondents were verbally informed that should they feel uncomfortable with any item in the questionnaire, they were free to skip that particular question. Finally, all respondents were informed that there were no risks or harm involved in participating in the study.

\section{Results}

\section{Socio-Demographic Characteristics of the respondents}

This section presents the socio-demographic characteristics of the respondents. From the analysis, the mean age of the respondents is 22.72 , while the standard deviation is 3.116. Table 2 indicated that majority of the respondent were between the ages of $18-21$ years (41.5\%) and $22-25$ years $(40.5 \%)$.

The other categories of the respondent's ages are presented in the table below. Concerning the gender of the respondents, Table 2 shows that the female (55.4\%) were higher than the male respondent $(44.6 \%)$. Also, the relationship status of respondents indicated that students that were not in any form of sexual relationship had the highest percentage (41.5\%). This is followed by those, who indicated that although they were in a relationship, they were not cohabiting with their sexual pattern (37.9\%). More so, only a small fragment of the respondents $(6.79 \%)$ were married. Christianity $(94.4 \%)$ is also the dominant religious affiliation of the respondents. 
Furthermore, table 2 illustrated that those in 200 level (30.3\%), 300 level (32.8\%) and 400 level (32.8\%) were the major respondents sampled in the study. Still, the average student in the study gets between N6,000-N10,000 (35.9\%) and N10,000-N15,000 (30.8\%) as their estimated monthly allowance. About half of the students sampled in the study were having a cumulative grade point average (CGPA) of 3.00-3.49 $(50.3 \%)$. Others can be found in the table below.

In the same vein, most of the students stated that they were on clear stand (72.8\%) while only a few of them indicated that they were on probation (0.5\%). Again the ethnic affiliations of the respondents indicated that more than half of the respondents were from ljo ethnic groupings (i.e. ljaw, Epie-Atiss, Ogbia, and Nembe) [56.4\%] the distribution of other ethnic groups can be found in table 2 above. With regards to residential pattern, the majority of the students opined that they were leaving off-campus (67.7\%). Additional, the study also demonstrated that more than half of the respondents were from polygamous homes (59.5\%). Finally, the majority of the students also indicated that they were currently using android phones (69.7\%).

\section{Social Media Use and Sex Partner}

The table 3 below shows the cross-tabulation of ever had a sex partner by social media use. The table showed that there is a significant relationship between level of social media account owned and ever had a sex partner, $(P<0.05)$, the table revealed that respondents who have had a sex partners have the highest number of social media account (62.1\%) than respondents who have never had a sexual partner (3.6\%).

Furthermore, there was no significant relationship between time spent on social media and ever had a sexual partner $(P>0.05)$, however, the table indicates that there was a significant relationship between activities done on social media and ever had a sexual partner $(P<0.05)$. The table shows that people who use the social media to chat (29.7\%) and send or receive pictures, videos and music (24.6\%) were more likely to have a sex partner than those who do other activities.

Nevertheless, there was no significant relationship between age at first social media use and ever had a sexual partner. Respondents who have had a sexual partner starting making use of social media platforms between the ages of 19-22yrs compare to those who have never had a sexual partner (52.6\%).

In the case of data usage, it had a significant relationship with ever had a sexual partner $(P<0.05)$, respondents who make use of the highest volume of data (67.2\%) have had a sexual partner. Again, there was no significant relationship between place of social media access and ever had a sexual partner $(P>0.05)$ given that those who access their social media in school have had a sexual partner (49.2\%).

Going furthermore, use of Facebook was significantly related to ever had a sexual partner $(P>0.05)$. The table shows that respondents who make use of Facebook on a higher rate have had a sexual partner (64.6\%). Nonetheless, the use of WhatsApp was significantly related to ever has a sexual partner 
$(P<0.05)$, the table shows that those who highly and moderately make use of WhatsApp have had a sexual partner (47.2\%) and (33.3\%) respectively.

The table also shows that the use of Instagram is not significantly related to ever had a sexual partner. $(P>0.05)$, However, the respondents who moderately make use of Instagram have had in sexual partner (35.4\%) compare to those who have not had a sexual partner (4.6\%). It was also revealed that the use of twitter is not significantly related to ever had sexual partner $(P<0.05)$, however, the table indicated that respondents who moderate make use of titter have had a sexual partner (34.4\%) finally, the use of YouTube is not significantly related to ever has a sexual partner $(P<0.05)$. however, the table shows that respondents who make use of twitter in a low rate have had a sexual partner (57.3\%).

\section{Level of Social Media Use}

Figure 1 below presents the level of social media use by the different social media platforms. The use of the Facebook platform (80\%) and WhatsApp's (54.4\%) had the highest numbers of respondents. While YouTube was the least used social media platforms by the respondents.

\section{Current and Previous Levels of Sex Partners}

Figure 2 presents the levels of both current and previous sexual partners. Majority of the respondents had a high level of previous sexual partners (47.7\%), followed by those with moderate sex partners $(42.1 \%)$. However, respondents with moderate current sexual partners were highest (51.3\%).

\section{Multiple Regression of Social Media use and Sexual Behaviour}

Model 1 presents the relationship between types of social media account used, time spent on social media and sexual behaviour. From the first model, the use of Facebook, Twitter and YouTube has no significant relationship with the sexual behaviour of the respondents. However, the use of WhatsApp is significantly related to sexual behaviour. Thus, those who moderately use WhatsApp as a social media application are 15.3 times more likely to exhibit high sexual behaviour than those with low usage, while those with high usage of WhatsApp are 39.8 times more likely to exhibit high sexual behaviour than those with low usage. By implication, those who spend more time on using WhatApps are more likely to exhibit high sexual behaviour like; having multiple sex partners, have had an abortion, use a condom, and engage in oral and anal sex and masturbation. Furthermore, the use of Instagram is also significantly related to sexual behaviour. Hence, respondents whose use of Instagram is high are $25 \%$ less likely to exhibit high sexual behaviour than respondents with low use of Instagram. Also, model 1 shows that respondents who spend the most time on social media are $12 \%$ less likely to exhibit high sexual behaviour than those who spent less time. 
Model 2 introduced two socio-demographic variables (gender and relationship status), to ascertain its effect on the observed relationship in Model 1. From the table below in model 2, the relationship between the use of WhatsApp and sexual behaviour disappeared when gender, relationship status, and faculty of respondents were introduced. However, the use of Instagram remained significant with sexual behaviour. Therefore, respondents high usage of Instagram, are 7\% less likely to exhibit high sexual behaviour that those with low usage. Besides, time spent on social media also remained significantly related to sexual behaviour.

Consequently, respondents who spend moderate time on social media are $19 \%$ less likely to exhibit high sexual behaviour than those who spend low time. Still, respondents who spend high time on social media are $6 \%$ less likely to engage in high sexual behaviour than those who spend low time.

Also, the relationship status of respondents is seen to be significantly related to sexual behaviour. Accordingly, respondents in a cohabiting relationship are $24.29 \%$ more likely to exhibit high sexual behaviour than those who are not into any form of relationship. More so, respondents who were in a relationship but not cohabiting are also 4.98 times more likely to exhibit high sexual behaviour than those who are not in any relationship.

\section{Discussion Of Findings}

Findings in this study could be compared to others. Firstly, this study revealed that Facebook is the most prevalent social media platform used by undergraduate students, while YouTube is the least. This finding is different from that of Amoo, Adetoro and Olawale-Isaac (2013) on effects of adolescents exposed to sexual content on social media in Nigeria who found out that YouTube is the most prevalent social media platform used among adolescent while Linkedln was the lowest. Nevertheless, the findings of Broom and Allen (2017) on social media and sexual behaviour among adolescents in the United States confirms the position of this study as it reported Facebook to be the most prevalent social media platform used by adolescent.

Also, while the findings in this study revealed that time spent on social media, age at first social media use, use of WhatsApp, use of Instagram, use of twitter, were significantly related to sexual behaviour of undergraduate students, the study of Broom and Allen (2017) on social media and sexual behaviour among adolescents in the United States, similarly found out that Facebook, Instagram were having a significant relationship with number of sexual partners. Also, Amoo, Adetoro and Olawale-Isaac (2014) study on the effects of adolescents exposed to sexual content on social media in Nigeria found out that Facebook has a significant relationship with sexual partners. Additionally, in this study it was discovered that there level of social media account, activities on social media, age at first social media use, data usage per month, place of social media access, use of Facebook, use of WhatsApp have significant relationship with the use of contraception (condom), these findings are similar to that of Oladeji and Ayangaunna (2017) on the media influence as predictors of adolescents sexual risky behaviour in Nigeria also shows that media content have a significant relationship with condom use, 
Furthermore, this study also shows that level of social media account owned, activities on social media, age at first social media use, data usage per month, place of social media access, use of Facebook, use of Instagram and use of twitter have a significant relationship with last time sexual intercourse. A similar finding, Oladeji and Ayangunma on media influence as predictors of adolescents sexual risky behaviour in Nigeria, the study shows that there is a significant relationship between media contents and sexual intercourse.

However the study also shows that level of social media, time spent on social media, activities on social media, data usage and use of WhatsApp is significantly related to ever had sexual intercourse, studies carried out by Asrese and Mekonnen (2018) on social network correlates of risky sexual behaviour among adolescents in Bahir Dar and Mecha Districts North East Ethiopia found out that social network has a significant relationship with ever had sex, also a study carried out by Nwagwu (2017) on social networking identity and sexual behaviour of undergraduates students in Nigerian Universities found out that social networking revealed that personal identity and social networking itself predicted ever had sex.

\section{Conclusion And Recommendations}

This study concluded that parameters such as spending time on social media platforms, prevalence of social media account, activities on social media, age at first social media use, place of social media access, use of Facebook, use of WhatsApp and use of Instagram is significantly associated with risky sexual behaviour such as numbers of sex partners, masturbation, oral sex etc, among undergraduate students.

Based on the findings from this study, the following recommendations have been made; Firstly, the youth should be aware that the media portrays more of sex inviting images that appeal to their emotion, thus, public enlightenment on the dangers of excessive exposure to the social media should be organized for undergraduates students.

Secondly, sex education should be introduced at all level of the educational systems in Nigeria, this will to a large extent expose undergraduate students to the dangers associated with certain dangerous sexual behaviour which is occasioned by exposure to the social media. Finally, universities in Nigeria should set up an effective counselling units to counsel students on the dangers social media pose to their sexual and reproductive health.

\section{Declarations}

\section{Acknowledgement}

The authors which to acknowledge the contributions of senior colleagues in the department of sociology, Niger Delta University who served as a third eye in making this work better. The contributions of our students who also served as research assistants is also well acknowledged. 


\section{Declaration}

The authors declare that no part of this article has been published or is under consideration for publication anywhere.

\section{Funding}

This article did not receive any funding from any group or individual

\section{Conflict of Interest}

The authors have no conflict of interest to declare

\section{Authors' contributions}

EU conceptualised and designed the study. ROE and EU analysed and interpreted the data. ROE and EU wrote the manuscript. All authors have critically reviewed and approved the final draft and are responsible for the content and similarity index of the manuscript.

\section{Compliance with Ethical Standards}

All research procedures performed in this study adheres to the ethical standard of the Niger Delta University, which is also in line with national code of conducting research in Nigeria. The research process is also in line with Helsinki 1964 declaration and its later amendments or comparable ethical standards.

\section{References}

Adebayo, D.O., Udegbe, I.B. \& Sunmola, A.M. (2006). Gender, Internet use, and sexual behaviour orientation among young Nigerians. Cyberpsychology \& Behavior, 9(6), 742-752.

Ajayi, O.T. (2010), "Use of social networking websites among tertiary institution students in Oyo State, Nigeria", M.Inf.Sc. project, Africa Regional Centre for Information Science, University of Ibadan.

Akhuetie, E.R., Uzobo, E., \& Ogbeide, F.W. (2017). Social media and online sexual predation in Benin city, Nigeria. Ilorin journal of sociology, 9 (1), 14-27

Amoo, E. O. Adetoto, G.W. \& Olawale-Isaac, A. (2013). Effects of Adolescents exposure to sexual contents through social media in Nigeria. Creativity Global Competitive Econonmies:2020 planning implementation. 2053-2061 Retrieved from http:// eprints. Covenant university. edu.ng/ 4021/1/Paper\%20203 \%20\%28 Amoo\%2 02013\%29.pdf.

Ashiekpe, A.J., \& Ugande, G.B (2017). Analysis of the effects of social media sexting on adolescents and youths sexual behaviours and attitudes towards sexuality in Nigeria. International Journal of Innovative Research and Advanced Studies, 4(1), 222-232 
Asrese, K., \& Mekonnen, A. (2018). Social network correlates of risky sexual behavior among adolescents in Bahir Darand Mecha Districts, North West Ethiopia: An institution-based study. Reproductive Health 15 (61), 1-8

Bailey, S., \& Barbara E. (2014). What is new media? New media institute. Retrieved from; http://www.newmedia.org/what-is-new-media.html.

Blanchard, O. (2011). Social media program development. In Social media ROl: managing and measuring social media efforts in your organization (pp. 3-13). Indianapolis, IN: Que.

Broom, M., \& Allen, N. (2017). Social media and sexual behaviour among adolescents Public Health Surveillance, 3(2), 28.

Brown, J.. \& L'Engle, K,(2009). Sexual attitudes and behaviors associated with U. S early adolescent exposure to sexually explicit media. Communication Research, 36(1), 129-151

Business Day (2013). "How Nigerian use social media" available at: www.businessdayonline.com/hownigerians-use- media.

Collins, R.L., Elliott, M.N., Berry, S.H., Kanouse, D.E., Kunkel, D., Hunter, S.B. \& Miu, A. (2004), Watching sex on television predicts adolescent initiation of sexual behavior, Pediatrics, 114 (3), 280-289.

France, A., \& Roberts, S. (2015). The problem of social generations: A critique of the new emerging orthodoxy in youth studies. Journal of youth studies, 18, 215-130

Galupo, M., Davis, K.S., Grynkiewicz, A.L. \& Mitchell, R.C. (2014), “Conceptualization of sexual orientation identity among sexual minorities: patterns across sexual and gender identity", Journal of Bisexuality, 14 (3/4), 433-456.

Hayes, J.A. (2010), "Risky sexual behaviors in adolescents: the impact of social and cultural capital", Master's degree thesis, Department of Sociology, CA State University, Sacramento, CA.

Iwokagh, S.N., Agbana, B., \& Agbana, B. (2014), New media interventions for adolescents reproductive and sexual health: evidence from Nigeria. International Conference on Communication, Media, Technology and Design, Istanbul, 24-26 April.

Kujuni, M. (2012), Online sexual activities and sexual risk-taking among adolescents and young adults in Lagos Metropolis, Nigeria. Africa Journal of Reproductive Health, 16(2), 207-218.

Katz, E., Gurevitch, M., \& Haas, H. (1973). On the use of the mass media for important things. American Sociological Review, 38, 164-181.

Lindsay, R.B. (2011). Social media and disaster: currents uses, future options and policy considerations (Congressional Research service Report for Congress). Congress Research Service. Retrieved from 
Livingstone, S., Haddon, L., \& Görzig, A. (2012). Children, risk and safety on the internet. Bristol, England: Policy Press.

Nissley, E. (2008). Study shows Internet Child Predators not necessarily posing asTeenagers. Citizens' Voice. Wilkes-Barre, Pa. p. T.26.

Nwagwu, W.Z (2017). Social networking, identity and sexual behaviour of undergraduate students in Nigerian universities. The Electronic Library, 35(3), 534-558

Oladeji, D., \& Ayangunna, J.A (2017). Media influence as predictors of adolescent's sexual risky behaviour in Nigeria. MOJ Women's Health. Available at; http://medcraveonline.com DOI:10.15406/mojwh.2017.05.00112

Park, N., Kee, K.F, \& Valenzuela, S. (2009). Being immersed in social networking environment: Facebook groups, uses and gratifications, and social outcomes. Cyberpsychology \& Behaviour, 12, 729-733.

Peter, J., \& Valkenburg, P. M. (2011). The use of sexually explicit internet materials and its antecedents: A longitudinal comparison of adolescents. Archives of Sexual Behaviour, 40, 1015-1025.

Ruggiero, T. E. (2000). Uses and gratifications theory in the 21st century. Mass communication and society, 3(1), 3-37

Wolak, J., Finkelhor, D,. Mitchell, K.J. (2008). Is talking online to unknown people always risky? Distinguishing online interaction styles in a national sample of youth internet users. Cyberpsychology \& Behavior. 11(3):340-343.

Wolak, J., Finkelhor, D., Mitchell, K. J., \& Ybarra, M. L. (2010). Online "predators" and their victims: Myths, realities, and implications for prevention and treatment. Psychology of Violence, 1, 13-35.

Wurtele, S. K., \& Kenny, M. C. (2010). Preventing online sexual victimization of youth. Journal of Behavior Analysis of Offender \& Victim: Treatment \& Prevention, 2(1), 63-73.

Wusu, O. (2013). Exposure to media content and sexual health behaviour among adolescents in lagos metropolis. African Journal of Reproductive Health, 13, 157-186.

\section{Tables}

Due to technical limitations, the tables are only available as a download in the supplemental files section.

\section{Figures}




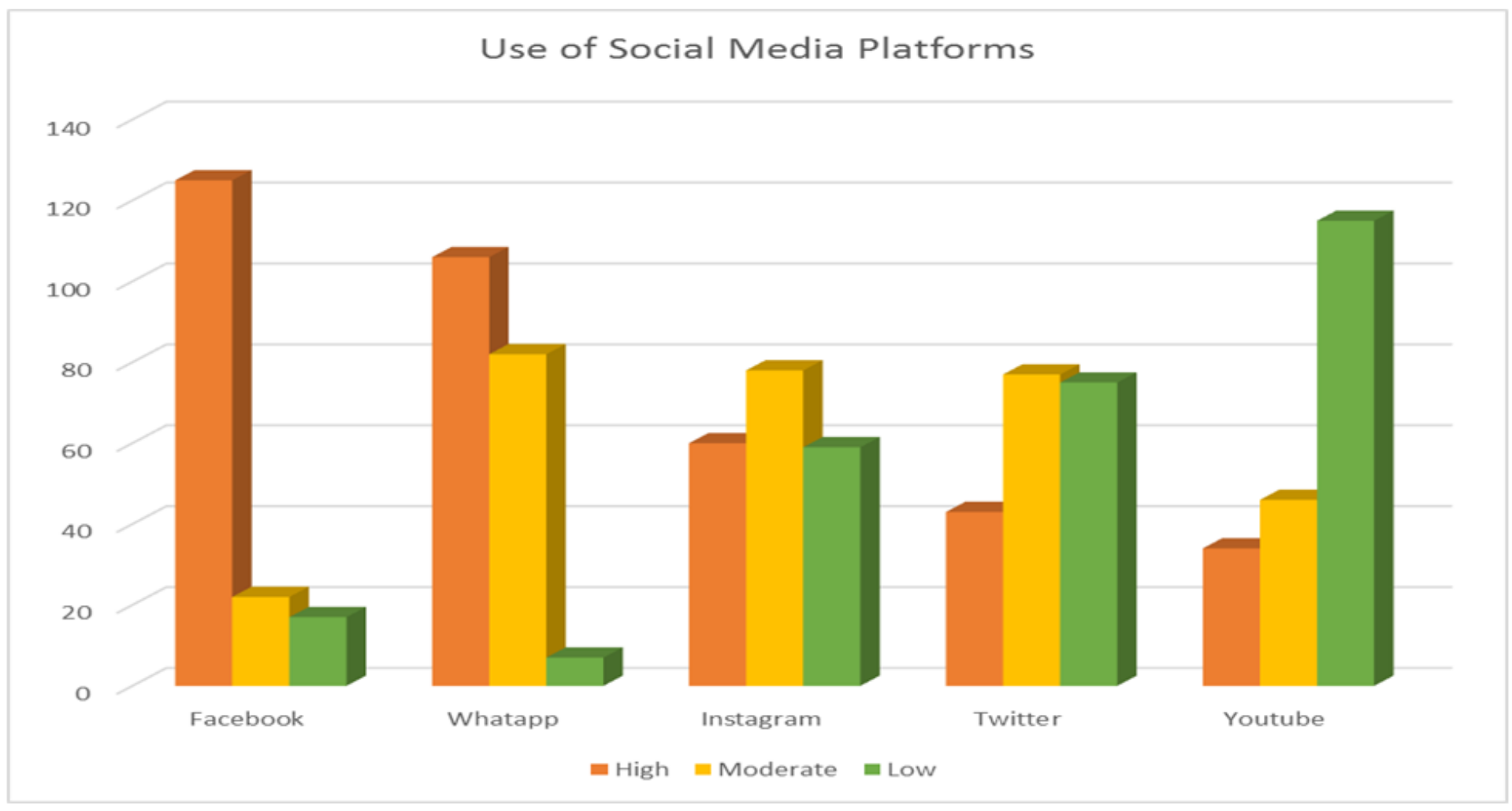

\section{Figure 1}

Level of social media platform use

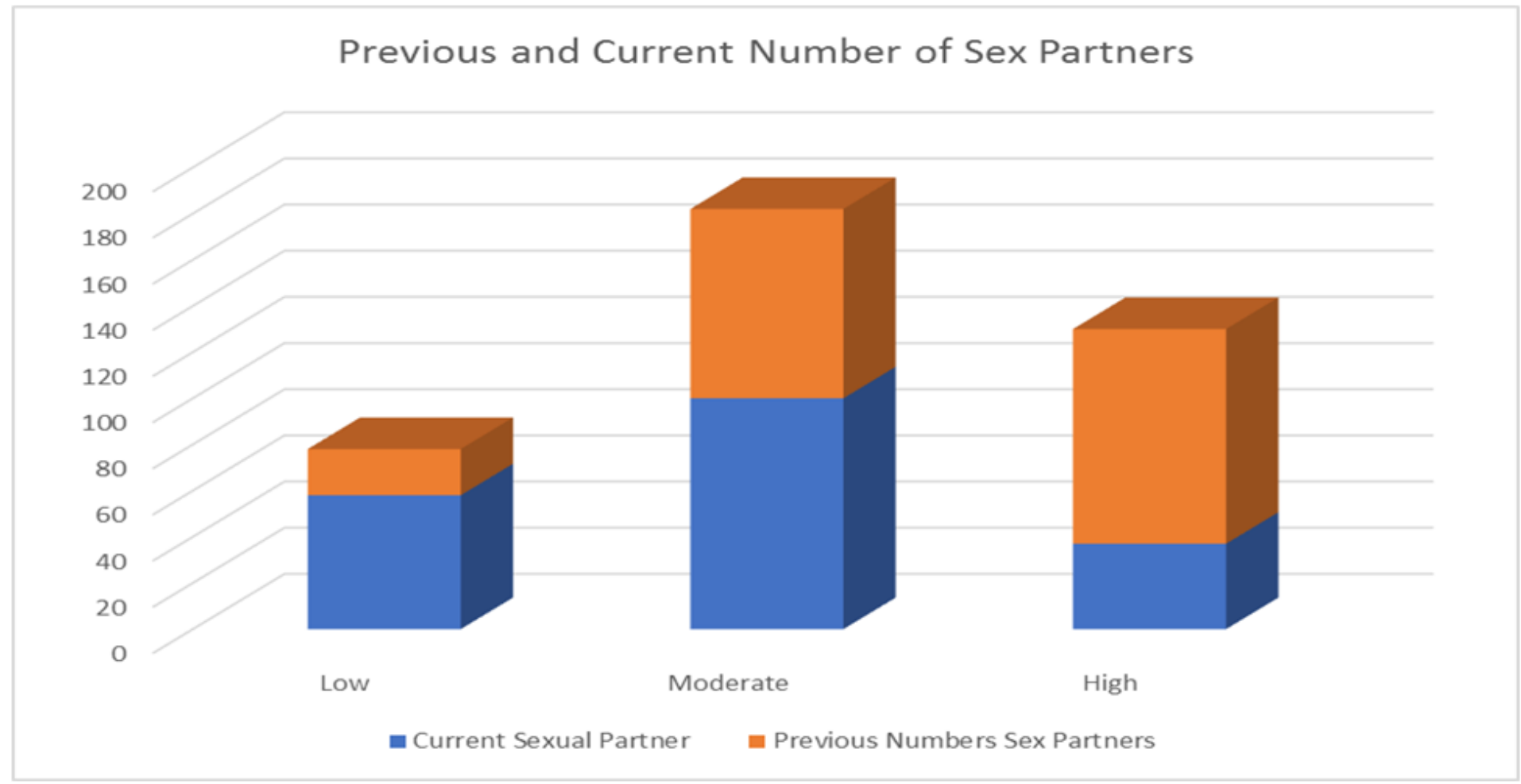

Figure 2 
Previous and Current levels of Sex Partners

\section{Supplementary Files}

This is a list of supplementary files associated with this preprint. Click to download.

- Tables.pdf 